\title{
E-cigarette use in patients receiving home oxygen therapy
}

\author{
Yves Lacasse MD MSc FRCP 1,2 , Martin Légaré MD FRCP ${ }^{3}$, François Maltais MD FRCP1,2
}

\begin{abstract}
Y Lacasse, M Légaré, F Maltais. E-cigarette use in patients receiving home oxygen therapy. Can Respir J 2015;22(2):83-85.

Current smokers who are prescribed home oxygen may not benefit from the therapy. In addition to being an obvious fire hazard, there is some evidence that the physiological mechanisms by which home oxygen is believed to operate are inhibited by smoking. Although their effectiveness is yet to be demonstrated, electronic cigarettes (e-cigarettes) are often regarded as an aid to smoking cessation. However, several burn accidents in e-cigarette smokers receiving home oxygen therapy have also been reported, leading Health Canada to release a warning of fire risk to oxygen therapy patients from e-cigarettes. It is the authors' position that patients receiving oxygen should definitely not use e-cigarettes. The authors provide suggestions for addressing the delicate issue of home oxygen therapy in current cigarette and/or e-cigarette smokers.
\end{abstract}

Key Words: Chronic hypoxemia; E-cigarette; Hazards; Oxygen therapy; Smoking

\author{
La cigarette électronique chez les patients sous \\ oxygénothérapie à domicile
}

Il se peut que les fumeurs qui se font prescrire une oxygénothérapie à domicile ne profitent pas de ce traitement. Sans compter que le tabagisme pose un risque d'incendie évident, certaines données probantes indiquent qu'il inhibe les mécanismes physiologiques par lesquels l'oxygénothérapie à domicile fonctionnerait. Même si son efficacité reste à démontrer, la cigarette électronique (vapoteuse) est souvent perçue comme une aide au sevrage du tabagisme. Cependant, plusieurs incidents de brûlure chez des vapoteurs sous oxygénothérapie à domicile ont été déclarés, ce qui a incité Santé Canada à publier une mise en garde sur les risques d'incendie que représente la cigarette électronique auprès de ces patients. De l'avis des auteurs, les patients sous oxygénothérapie ne devraient absolument pas vapoter. Les auteurs donnent des suggestions pour aborder le problème délicat de l'oxygénothérapie à domicile chez les fumeurs ou les vapoteurs.

\section{CLINICAL PROBLEM}

In 2006, the death of two patients registered to our respiratory home care program stimulated our reflection regarding oxygen therapy in current smokers (1). Both had oxygen-dependent chronic obstructive pulmonary disease (COPD) and died from severe burns and inhalation injuries that occurred while they were receiving oxygen administered from a home oxygen concentrator. The inquiries revealed that both were smoking when the accidents happened and that their oxygen concentrators were functioning properly.

Since then, the rules of prescription for home oxygen therapy have changed in Quebec (2). Although the provincial terms of reference now indicate that home oxygen is not indicated in current smokers, oxygen therapy remains a problem in patients addicted to tobacco. We have witnessed patients resume smoking after long-term oxygen therapy (LTOT) is initiated, especially when oxygen was prescribed at the outset of a hospitalization for acute COPD exacerbation complicated by severe hypoxemia, and during which the patient was abstinent. Similarly, we are aware of COPD patients who were enrolled into our ongoing randomized, placebo-controlled trial investigating nocturnal oxygen (the INOX trial [ClinicalTrials.gov NCT01044628]) returning to cigarette smoking after at least six months of abstinence. In this regard, we were recently asked whether patients receiving home oxygen therapy could be allowed to replace cigarettes with e-cigarettes.

\section{ARE THERE REALLY CURRENT SMOKERS RECEIVING OXYGEN THERAPY?}

Smoking in patients on home oxygen is not a rare occurrence. In the few reports that specifically addressed this issue, this proportion reached almost 20\% (3). Such is our own experience (4). Because oxygen accelerates combustion, it is an obvious fire hazard. Several reports highlighting the risks of burn in patients who smoke while receiving oxygen therapy have been published (5).

Why do physicians still prescribe home oxygen therapy to current smokers even if it is dangerous? An explanation may be that in the
British Medical Research Council's trial of LTOT in COPD (6), smoking was not an exclusion criterion, although at study entry all patients were "urged to give up smoking" . It turned out that 37 of the 87 (43\%) patients were counted as current smokers. Smoking was not identified as a predictor of mortality in this trial. Although no mention of patients' smoking status was made in the original Nocturnal Oxygen Therapy Trial (NOTT) article (7), a secondary publication indicated that $38 \%$ of participants were active smokers at study entry (8). Hence, these two landmark trials have set precedents that remain accepted in clinical practice.

\section{SMOKERS MAY NOT BENEFIT FROM OXYGEN THERAPY}

There is sparse but convincing evidence that cigarette smoking determines the severity of secondary polycythemia in patients with hypoxemic COPD and that smoking prevents its correction by LTOT (9). Secondary polycythemia only represents a surrogate outcome, and this study did not demonstrate that, when on LTOT, nonsmokers live longer than smokers. Nevertheless, this study suggested that the physiological mechanisms by which home oxygen is believed to operate are inhibited by smoking. It is, therefore, very likely that the treatment effect of both the British and the NOTT trials was diluted by the inclusion of current smokers. Unfortunately, the evidence that nonsmokers on LTOT fare better than smokers on LTOT will never come from randomized controlled trials.

E-CIGARETTES AS AN AID TO SMOKING CESSATION? Currently, there is evidence from only two randomized trials that e-cigarettes may help smokers stop smoking $(10,11)$. Only the trial by Bullen et al (10) included smokers motivated to quit; the trial by Caponnetto et al (11) included smokers not intending to quit, a situation that limits its scope. In the Bullen et al (10) trial ( $n=657$ patients), six-month continuous abstinence was observed in $7.3 \%$ of those allocated to nicotine e-cigarette (16 mg), $4.1 \%$ of those on placebo e-cigarette and $5.8 \%$ of those treated with nicotine patches $(21 \mathrm{mg})$. The difference in abstinence rate between nicotine e-cigarette and

${ }^{1}$ Centre de recherche; ${ }^{2}$ Respiratory Home Care Programme, Centre de pneumologie, Institut universitaire de cardiologie et de pneumologie de

Québec; ${ }^{3}$ Critical Care Medicine, Hôpital Maisonneuve-Rosemont, Montréal, Québec

Correspondence: Dr Yves Lacasse, Centre de Pneumologie, Institut universitaire de cardiologie et de pneumologie de Québec,

2725 Chemin Ste-Foy, Ste-Foy, Quebec G1V 4G5. Telephone 418-656-4747, fax 418-656-4762, e-mail yves.lacasse@med.ulaval.ca 
nicotine patches was not statistically significant (difference $1.5 \%$ [95\% CI $-2.5 \%$ to $5.5 \%]$ ). In the Cochrane review summarizing these two trials, McRobbie et al (12) concluded that the small number of trials, low event rates and wide CIs around the estimates were limitations to the interpretation of their meta-analysis. Current evidence from randomized controlled trials supporting the use of e-cigarettes as an aid to smoking cessation is, therefore, scant and, overall, inconclusive.

Also, the long-term health impact of e-cigarettes, for users and the public, cannot be determined from the currently available data (13). We know that carboxyhemoglobin levels rapidly decrease in individuals who exchange cigarettes for e-cigarettes (14), a phenomenon that can only facilitate oxygen transportation. However, vaping may not be that innocuous because it may induce oxidative stress and inflammation in the lungs (15).

Fortunately, the scientific literature related to e-cigarettes is rapidly evolving. As of January 15, 2015, 172 intervention studies using e-cigarettes were registered on ClinicalTrials.gov - the United States National Institutes of Health registry and results database of publicly and privately supported clinical studies involving human participants conducted around the world. Our understanding of the indications, benefits and risks of e-cigarettes will certainly improve as the results of these trials are published.

\section{HAZARDS OF E-CIGARETTES IN CURRENT SMOKERS}

In the meantime, what is the best advice to our patients receiving home oxygen therapy who would be tempted to vape instead of smoke? The answer begins with the elementary description of the typical e-cigarette. The basic components of most disposable or rechargeable e-cigarettes include a cartridge containing a liquid solution of propylene glycol (with or without nicotine), a battery and a heating element (16). This latter component reaches high temperature and aerosolizes the e-liquid to be inhaled. Consequently, it can conceivably ignite in the presence of oxygen. Although the human health effects of e-cigarettes have already been the subject of studies and at least one systematic review (13), we could not retrieve any case report of burn accident in e-cigarette smokers on home oxygen in a Medline search. However, a quick 'Google' search was sufficient to identify several reports of such accidents in the lay press $(17,18)$.

Several other cases may have been encountered around the world and left unreported, including a 72-year-old patient with pulmonary fibrosis who was seen by one of the authors when brought to Maisonneuve-Rosemont Hospital in Montreal (Quebec) with facial burns that occurred after his nasal prongs caught on fire when he was vaping while receiving oxygen through his concentrator at a flow rate of $6 \mathrm{~L} / \mathrm{min}$. This man was discharged from hospital five days later. This incident was reported to Health Canada, the Canadian health regulation authority that has since released a warning of fire risk to oxygen therapy patients from e-cigarettes (19). Burn accidents in patients receiving oxygen therapy are, therefore, not only plausible, they have occurred. In addition, battery fire and explosion from a defect known as 'thermal runaway' have been described (16). It is, therefore, our position that patients receiving oxygen therapy should definitely not use e-cigarettes.

\section{TENTATIVE RECOMMENDATIONS}

The provision of home oxygen therapy to active smokers (including those who use e-cigarettes) remains a difficult issue. We cannot provide firm recommendations but only some suggestions. First, we would not typically screen for resting hypoxemia in stable patients who smoke. Advantages of home oxygen must be balanced against its risks; arterial blood should be drawn only in patients in whom a clear advantage of oxygen therapy is expected to occur. If it is believed that the patient will not comply with the safety procedures and, especially if there is good reason to believe that the patient will smoke or vape while on oxygen, then it is medically justifiable not to prescribe it. Second, the indication for home oxygen therapy must be clearly ascertained if it is to be offered despite active smoking. In our opinion, indications of home oxygen therapy that are not clearly evidencebased should be reconsidered. An example would be the prescription of oxygen to prevent exercise-induced desaturation. Third, if severe hypoxemia persists at the outset of a hospitalization for an acute exacerbation of COPD, active smokers may often be discharged safely without oxygen following a short period of observation without oxygen, especially when their partial pressure of arterial oxygen approaches $55 \mathrm{mmHg}$. Fourth, if oxygen therapy is prescribed in such circumstances, systematic reevaluation following the initial prescription of oxygen therapy made within the course of an acute exacerbation of COPD is mandatory because at least $30 \%$ of patients meeting the criteria for domiciliary oxygen at hospital discharge will no longer need this therapy after a few months of stability $(20,21)$. This should also offer the opportunity to reassess smoking status and to carefully reconsider the utility of oxygen therapy in patients who have resumed smoking while recovering from the exacerbation, irrespective of the presence or absence of blood gas indications for LTOT.

AUTHOR CONTRIBUTIONS: All authors contributed equally to this article.

\section{REFERENCES}

1. Lacasse Y, LaForge J, Maltais F. Got a match? Home oxygen therapy in current smokers. Thorax 2006;61:374-5.

2. Ministère de la Santé et des Services Sociaux du Québec. Programme national d'oxygénothérapie à domicile: cadre de référence. $2011<$ http://publications.msss.gouv.qc.ca/acrobat/f/ documentation/2011/11-935-01W.pdf> (Accessed October 20, 2014).

3. Cornette A, Petitdemange I, Briancon S, Burlet C, Polu JM. [Evaluation of smoking in chronic severe respiratory insufficiency patients treated with long-term oxygen at home]. Rev Mal Respir 1996;13:405-11.

4. Lacasse Y, Lecours R, Pelletier C, Begin R, Maltais F. Randomised trial of ambulatory oxygen in oxygen-dependent COPD. Eur Respir J 2005;25:1032-8.

5. West GA, Primeau P. Nonmedical hazards of long-term oxygen therapy. Respir Care 1983;28:906-12.

6. Medical Research Council Working Party. Long term domiciliary oxygen therapy in chronic hypoxic cor pulmonale complicating chronic bronchitis and emphysema. Report of the Medical Research Council Working Party. Lancet 1981;1:681-6.

7. Nocturnal Oxygen Therapy TrialGroup. Continuous or nocturnal oxygen therapy in hypoxemic chronic obstructive lung disease: A clinical trial. Nocturnal Oxygen Therapy Trial Group. Ann Intern Med 1980;93:391-8.

8. McSweeny AJ, Grant I, Heaton RK, Adams KM, Timms RM. Life quality of patients with chronic obstructive pulmonary disease. Arch Intern Med 1982;142:473-8.

9. Calverley PM, Leggett RJ, McElderry L, Flenley DC. Cigarette smoking and secondary polycythemia in hypoxic cor pulmonale. Am Rev Respir Dis 1982;125:507-10.

10. Bullen C, Howe C, Laugesen M, et al. Electronic cigarettes for smoking cessation: A randomised controlled trial. Lancet 2013;382:1629-37.

11. Caponnetto P, Campagna D, Cibella F, et al. EffiCiency and Safety of an eLectronic cigAreTte (ECLAT) as tobacco cigarettes substitute: A prospective 12-month randomized control design study. PLoS One 2013;8:e66317.

12. McRobbie H, Bullen C, Hartmann-Boyce J, Hajek P. Electronic cigarettes for smoking cessation and reduction. Cochrane Database Syst Rev 2014;12:CD010216.

13. Callahan-Lyon P. Electronic cigarettes: Human health effects. Tob Control 2014;23(Suppl 2):ii36-40.

14. van Staden SR, Groenewald M, Engelbrecht R, Becker PJ, Hazelhurst LT. Carboxyhaemoglobin levels, health and lifestyle perceptions in smokers converting from tobacco cigarettes to electronic cigarettes. S Afr Med J 2013;103:865-8.

15. Vardavas CI, Anagnostopoulos N, Kougias M, Evangelopoulou V, Connolly GN, Behrakis PK. Short-term pulmonary effects of using 
an electronic cigarette: Impact on respiratory flow resistance, impedance, and exhaled nitric oxide. Chest 2012;141:1400-6.

16. Brown CJ, Cheng JM. Electronic cigarettes: Product characterisation and design considerations.

Tob Control 2014:23(Suppl 2):ii4-10.

17. Daily Mail Reporter. OAP engulfed in flames and seriously burned after her e-cigarette ignites oxygen at Manchester hospital. 2014; $<$ www.dailymail.co.uk/news/article-2603975/OAP-engulfed-flamesseriously-burned-e-cigarette-ignites-oxygen-Manchester-hospital. html> (Accessed October 20, 2014).

18. Mulder JT. Syracuse hospital bans e-cigarettes after patient on oxygen catches fire while using one. 2014 <www.syracuse.com/news/ index.ssf/2014/04/syracuse_hospital_bans_e-cigarettes_after_ patient_catches_fire_while_using_one.html> (Accessed October 20, 2014).
19. Health Canada. Consumer Product Update: Health Canada warns of fire risk to oxygen therapy patients from electronic cigarettes and other electrical devices. $2014<$ http://healthycanadians.gc.ca/recallalert-rappel-avis/hc-sc/2014/42671a-eng.php> (Accessed November 25, 2014).

20. Eaton TE, Grey C, Garrett JE. An evaluation of short-term oxygen therapy. The prescription of oxygen to patients with chronic lung disease hypoxic at discharge from hospital. Respir Med 2001;95:582-7.

21. Levi-Valensi P, Weitzenblum E, Pedinielli JL, Racineux JL, Duwoos H. Three-month follow-up of arterial blood gas determinations in candidates for long-term oxygen therapy. A multicentric study. Am Rev Respir Dis 1986;133:547-51. 


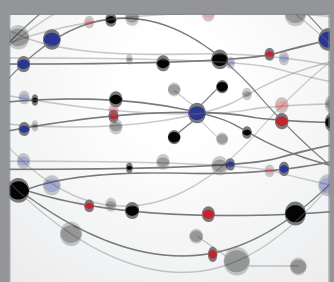

The Scientific World Journal
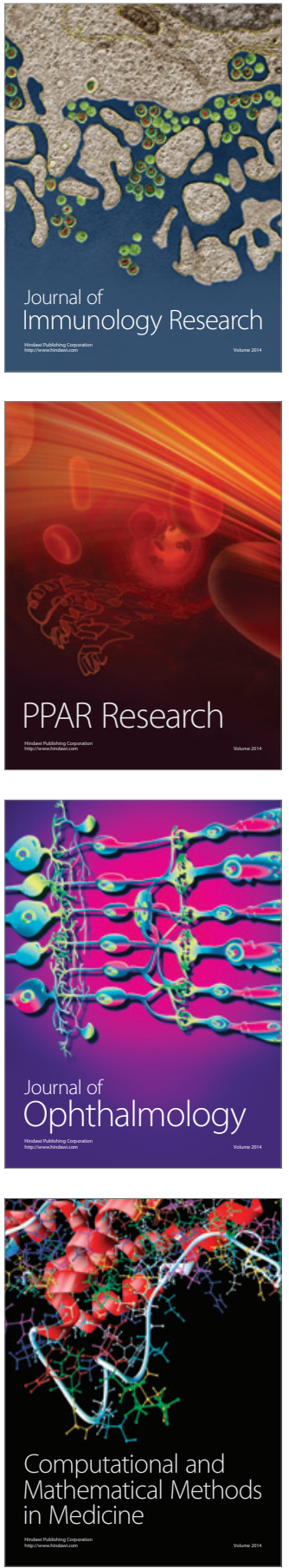

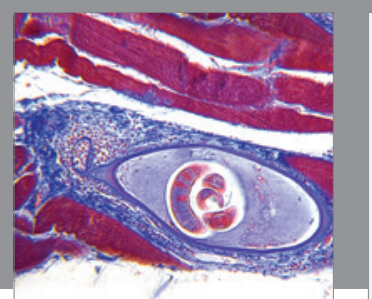

Gastroenterology Research and Practice

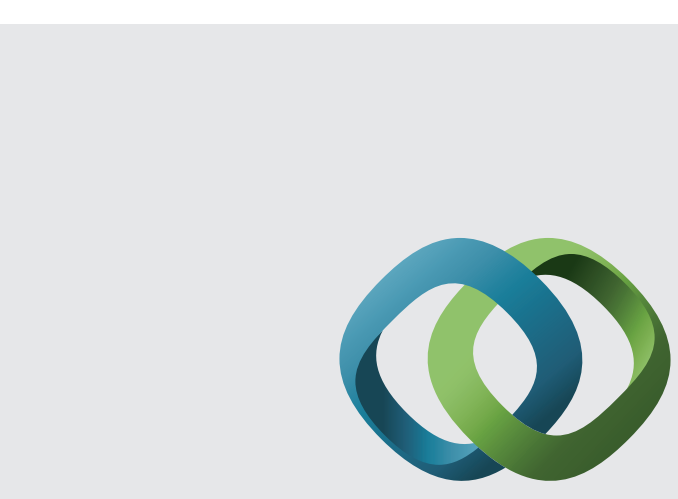

\section{Hindawi}

Submit your manuscripts at

http://www.hindawi.com
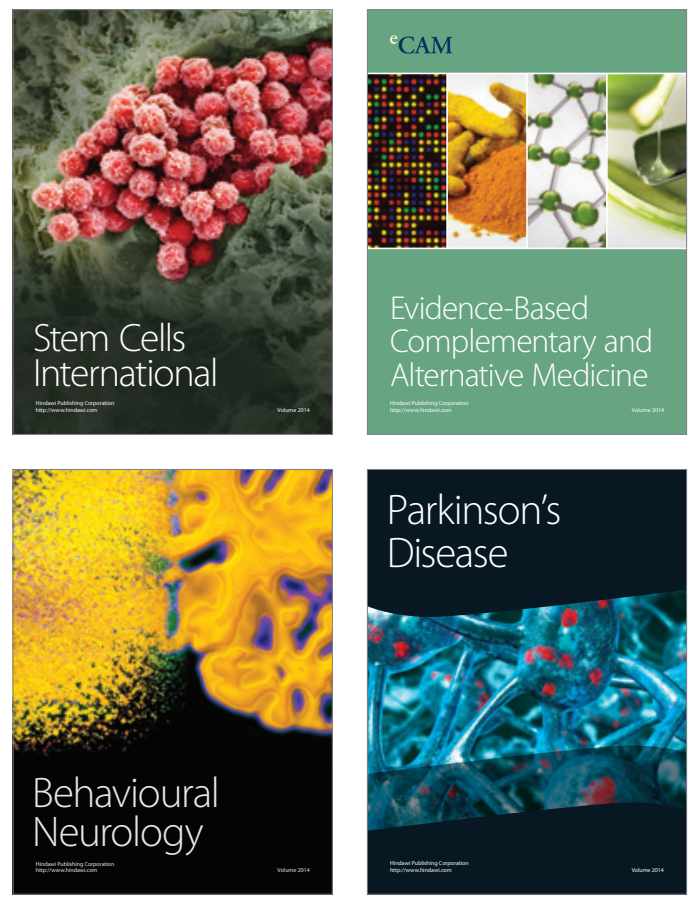
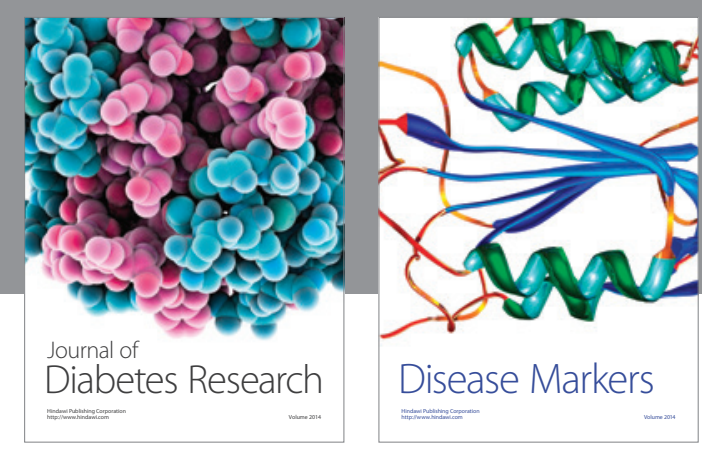

Disease Markers
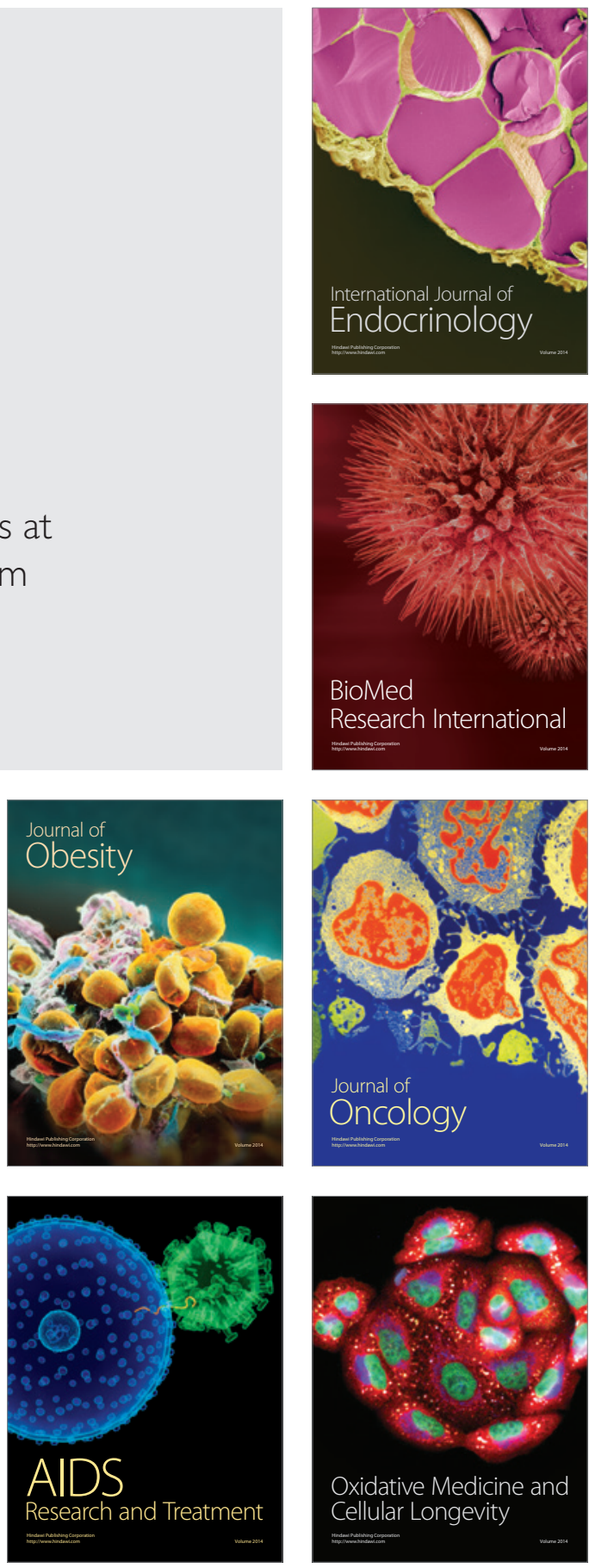